\title{
Flux measurements in the surface marine Atmospheric Boundary Layer over the Aegean Sea, Greece
}

\author{
V.E. Kostopoulos *, C.G. Helmis \\ Department of Environmental Physics and Meteorology, Faculty of Physics, University of Athens, University Campus, Build, PHYS-5, Zografou, 15784, Athens, Greece
}

\section{H I G H L I G H T S}

- We found that the short fetch of air flow affects the regional air-sea exchanges.

- Latent heat fluxes were influenced by the intense SST spatial variability.

- The drag coefficient was found to be a constant function of wind speed.

\section{A R T I C L E I N F O}

\section{Article history:}

Received 2 April 2014

Received in revised form 22 June 2014

Accepted 28 June 2014

Available online $\mathrm{xxxx}$

Editor: Pavlos Kassomenos

\section{Keywords:}

Momentum heat and humidity fluxes

Drag coefficient

Aegean Sea

\begin{abstract}
A B S T R A C T
Micro-meteorological measurements within the surface Marine Atmospheric Boundary Layer took place at the shoreline of two islands at northern and south-eastern Aegean Sea of Greece. The primary goal of these experimental campaigns was to study the momentum, heat and humidity fluxes over this part of the north-eastern Mediterranean Sea, characterized by limited spatial and temporal scales which could affect these exchanges at the air-sea interface. The great majority of the obtained records from both sites gave higher values up to factor of two, compared with the estimations from the most widely used parametric formulas that came mostly from measurements over open seas and oceans. Friction velocity values from both campaigns varied within the same range and presented strong correlation with the wind speed at $10 \mathrm{~m}$ height while the calculated drag coefficient values at the same height for both sites were found to be constant in relation with the wind speed. Using eddy correlation analysis, the heat flux values were calculated (virtual heat fluxes varied from -60 to $40 \mathrm{~W} / \mathrm{m}^{2}$ ) and it was found that they are affected by the limited spatial and temporal scales of the responding air-sea interaction mechanism. Similarly, the humidity fluxes appeared to be strongly influenced by the observed intense spatial heterogeneity of the sea surface temperature.
\end{abstract}

(c) 2014 Elsevier B.V. All rights reserved.

\section{Introduction}

It is well known that air-sea interaction strongly influences the world's climate. The complexity of the physical processes involved, is still not fully understood although numerous studies addressed this issue over the past decades (Foreman and Emeis 2010, Smith et al. 1996). Flux measurements of mass and energy within the surface Marine Atmospheric Boundary Layer (MABL) are of fundamental importance in order to understand its structure and characteristics. They are considered essential for weather and climate predictions since they provide to models parameterization schemes for surface turbulent fluxes of momentum, heat and water vapor. The accurate prediction, particularly of momentum flux, is of crucial importance since it affects additionally, heat and water vapor vertical transportation as well as wave generation and upper sea circulation.

\footnotetext{
* Corresponding author. Tel.: + 302107276850 .

E-mail address: vkostopoulos@phys.uoa.gr (V.E. Kostopoulos).
}

Momentum transfer within the surface MABL is usually parameterized in terms of drag coefficient $\left(C_{D}\right)$, which is defined as,

$\mathrm{C}_{\mathrm{D}}=-\overline{\mathrm{u}^{\prime} \mathrm{w}^{\prime}} / \rho \mathrm{U}^{2}$

where $\overline{\mathrm{u}^{\prime} \mathrm{w}^{\prime}}$ is the momentum flux at the sea surface, $\rho$ is the air density and $U$ is the mean wind speed at a reference height $(10 \mathrm{~m})$. Drag coefficient parameterization is in the form of a linear function of wind speed mostly for high wind speed values (Smith 1980) while at moderate wind speed, many investigators have proposed constant values (Large and Pond 1981). It is worth mentioning that, $C_{D}$ depends on stability and together with wind speed are both usually corrected and their neutral values are estimated (see Section 2.3). Geernaert and Katsaros (1986) suggested that since wind stress varies with stability for equal wind speed reference, the sea state or the surface roughness must also vary and the final drag coefficient should be calculated from the neutral drag coefficient and the stability. On the other hand, Sethuraman and Raynor (1975) reported that for height less than $10 \mathrm{~m}$, wind profiles 
were found to follow logarithmic low even for moderately stable conditions $(z / L<0.1)$. They suggested that $C_{D}$ estimations from different campaigns that stand for near neutral conditions, do not really suffer from large deviations due to stability, comparing to the increase of the resulting uncertainty that comes with corrections.

The choice of using the drag coefficient regression equation under neutral conditions is regionally dependent (Byrne 1983, Geernaert and Plant 1990) and recent studies underline the need of improved parameterization (Edson et al. 2007). The differences that were found between independent experiments are thought to be a function of the sea state (Drennan et al. 2003, Foreman and Emeis 2010, Hwang 2005). The fetch or the duration of air flow over sea plays crucial role to the development of the wave field and the momentum transfer of short fetched flows is documented to be greater over young and developing wave fields than over older wave fields, which are in equilibrium with the wind (Drennan et al. 2003, Hwang 2005, Smedman et al. 2003 , Vickers and Mahrt 1997a). Sea surface motion due to waves is additionally an important parameter since the relation between wave phase speed and wind speed can significantly alter the wind profile. Vickers and Mahrt (1997a) noticed that the young age of wind driven waves could also be the result of phase speed reduction caused by wave breaking that usually accompanies wind accelerations and may be site specific. There have been several promising attempts lately towards parameterization of $C_{D}$ in terms of wave parameters such as age, height or steepness of the wave (Gao et al. 2009, Hwang et al. 2011).

Besides momentum transfer, significant amount of sensible and latent heat are also exchanged at the air-sea interface. Heat fluxes are driven by the air-sea temperature difference and enhanced with increased turbulent mixing over the sea. Under strong winds and consequent wave breaking, sea spray effects are also thought to include a significant contribution to heat exchange, besides the transfer at the interface (Andreas 2010). Over open and homogenous seas, the surface MABL was found mostly under neutral conditions. Near ocean currents, the air flow along large sea surface temperature (SST) gradients, changes the characteristics of the air masses and heat fluxes are produced due to the advection of air over sea surfaces with different temperatures (Small et al. 2008). The Frontal Air-Sea Interaction Experiment (FASINEX), among other studies, revealed the response of the lower marine atmospheric boundary layer to sharp changes in SST. Frieche et al. (1991) reported that for flow towards warm water, a well-mixed thermal internal boundary layer (TIBL) can form presenting upward heat fluxes while the main boundary layer height and air temperature and moisture content increases. Along SST gradients, resulting spatial pressure differences have also been recognized due to differential surface heating that can induce wind speed acceleration towards the warm side and increase turbulence (Small et al. 2008). For air flow towards cooler water, a shallow, stable TIBL is reported with typically lower air temperature and moisture, while increased stability can force the initiation of Low-Level Lets (LLJ) above the surface layer (Vihma et al., 1998). Increased temperature differences over the sea and responding stable or unstable conditions are also usually found downwind of any mainland, similar due to advection.

Up today, the vast majority of relevant studies were conducted mostly over open seas and oceans. Only two relative experimental expeditions have been reported over the Mediterranean, both at its western part (Drennan et al. 2003). During the FETCH experiment that took place in the Gulf of Lion (Fig. 1), mainly near neutral and unstable conditions were observed, with the latter corresponding to downward heat fluxes (Pedreros et al. 2003). These conditions were attributed to the negative air-sea temperature differences that resulted due to cold outbreaks of strong Mistral winds. The air-sea heat exchanges were also found to be influenced from the presence of intense orography and sheltered regions upwind the Gulf, according to Hauser et al. (2003). Regarding momentum transfer, the results from this campaign based on measurements around $50 \mathrm{~km}$ southerly from the coasts of south France, underlined the significance of wave age effects on the drag coefficient, which was found weaker under longer fetched (south-westerly flows) than under the much sorter fetched northern flows at common wind speed range (Drennan et al. 2003). The impact of wave age to the drag coefficient over the waters of the Mediterranean was already been pointed out from the early study of Volkov (1970). Similar conclusions came also from the Östergarnsholm field experiment in the Baltic Sea which has relative scales (Smedman et al. 2003). It is worth to notice that both the Baltic and western Mediterranean Sea, lack of the complex topography found over the Aegean Sea and this seems to both areas act favourable for the longer waves to gain importance and have an impact on the wind profile, by reducing the total drag with growing fetch due to swell formation. Thus, it is evident that the air-sea interaction mechanism over a semi-closed sea as the Aegean with complex topography will be probably sensitive to the local fetch and the local scales in time and space. Regarding the relation of the drag coefficient with wind speed, in the case of growing seas which are very frequent in coastal and bounded regions, Smedman et al. (2003) observations resembled the air flow over the Baltic as over

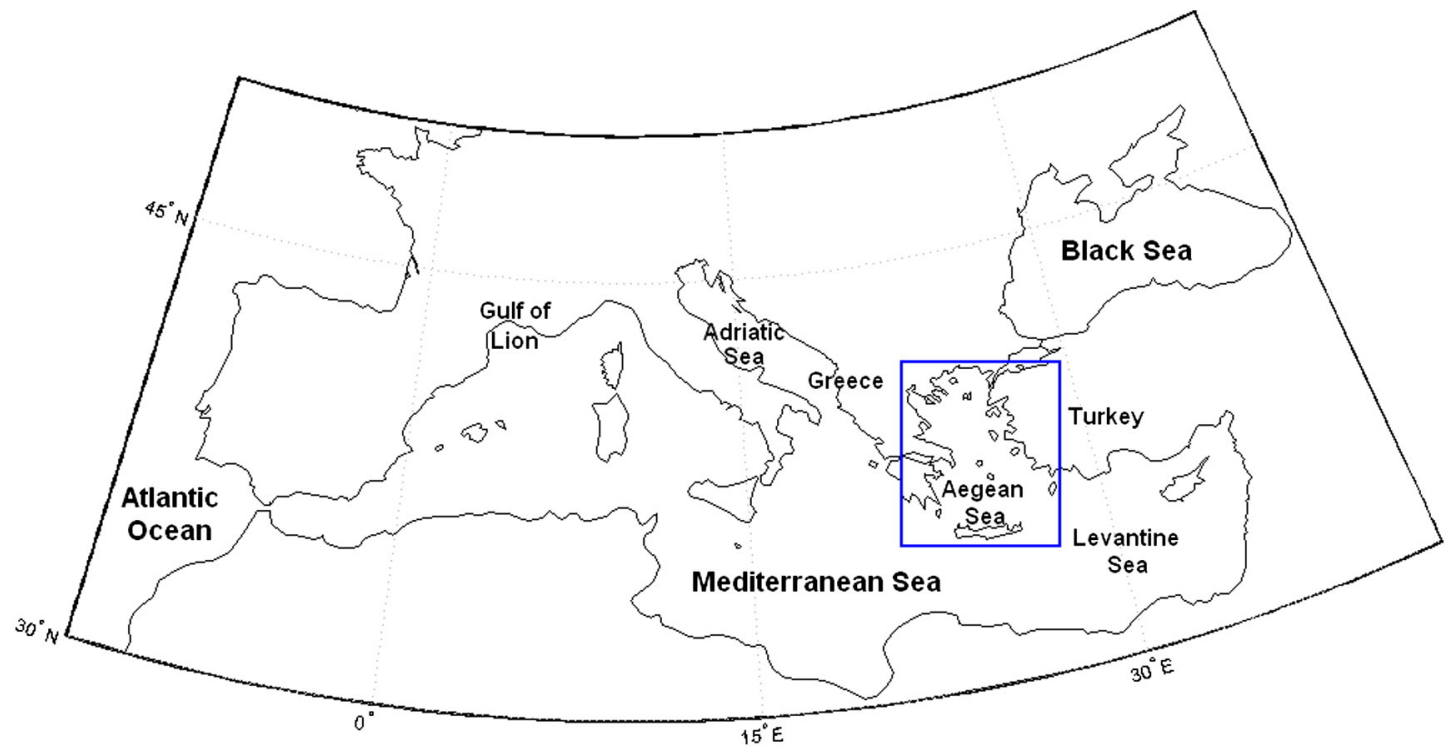

Fig. 1. The Aegean Sea, located at the north-eastern Mediterranean Sea. 
a solid, rough surface, in accordance with the wide accepted constancy or near constancy of the drag coefficient with wind speed, for moderate winds (Pond and Pickard, 1983). Under a different point of view and for stronger winds, the study of Foreman and Emeis (2010) that used data from different experiments of various fetch (including Östergarnsholm field and FETCH experiment), illustrated the corresponding variety of momentum fluxes and they showed that over the rough flow regime, e.g. for $\mathrm{U}>8 \mathrm{~m} / \mathrm{s}$ and $\mathrm{u} *>0.27 \mathrm{~m} / \mathrm{s}$, a linearity exists between $\mathrm{u}^{*}$ and wind speed of the examined data sets.

The complex topography of the Aegean Sea and the special oceanographic features that consist of different spatial (up to $10^{2} \mathrm{~km}$ ) and temporal scales (Sofianos et al.2002), shorter than the world oceans or even compared to the rest of Mediterranean Sea, is expected to have different impact on the exchanges at the air-sea interface. The two experimental campaigns at the north and the south-eastern Aegean Sea provided measurements with different fetch but of similar scales of air-sea interaction and is worth to mention that there are no other published measurements over this region. The primary goal of this work is to investigate the characteristics of the wind stress over the Aegean Sea and propose a regional bulk parameterisation with wind speed. Additionally, the surface heat fluxes are studied in relation to the variable air-sea temperature differences found over the Aegean, due to the limited scales of the basin and to the increased SST variability.

\section{Field data}

\subsection{The Aegean Sea}

The Aegean Sea is located at the north-eastern Mediterranean Sea, extends $600 \mathrm{~km}$ longitudinally and $300 \mathrm{~km}$ latitudinally between the main lands of Greece and Turkey, with approximately 3.000 islands and isles (Fig. 1). The Aegean waters present complex and variable circulation patterns and have an intense SST spatial variability (more details will be given). A surface thermal seasonal cycle is found climatologically to extend from north to south (during October to May) and from east to west (during June to September) while the satellite observations from 1985 to 2006 indicate that SST maximum changes are found during August (Skliris et al. 2011). According to Sofianos et al. (2002), the intense SST variability of the Aegean waters is mostly attributed to the entering of Black Sea waters through Dardanelles Strait at the north, the warm Levantine (Fig. 1) waters through eastern Crete straits and the upward transports of deep cold water due to the turbulent mixing and upwelling processes mostly during summer along the eastern coasts of the basin, due to stronger northerly winds, the etesians (also known as meltemi).

On annual mean basis, north winds prevail over the Aegean, its strength and persistence maximum values occur during the middle of winter and summer, while the wind speed maximum is observed over the center Aegean along its central axis. During summer, the seasonal etesian winds that are caused by the interaction of the thermal low of India and the high pressure field of the Azores or by the dominance of one of them, start from June and last until October (Rizou et al. 2013). Their sequence and intensity increase and maintain high levels until the middle of September, when they start to decay. In general they blow from north to northeast directions and their highest intensities occur during daytime while during night the wind speed usually decreases.

\subsection{Experimental sites and Instrumentation}

The island of Skyros hosted the first experimental campaign, from August 29 until September 10, 2011. This island is located at the northern Aegean (Fig. 2) and the experimental site was located at the northeastern part of the island, an area of more than $1 \mathrm{~km}^{2}$ with mean altitude less than $10 \mathrm{~m}$ with gentle slope at a distance of several hundred meters to few kilometers from ground elevations (Fig. 3a). Data corresponding to wind direction values, which are related with small reefs located downwind a few hundred meters off shore, was excluded from the analysis while pure marine flow was expected to have for wind direction values between 20 to 67 degrees. The second campaign took place from July 30 to August 9, 2012, at Karpathos Island at the south eastern Aegean, approximately $150 \mathrm{~km}$ from the centre Aegean (Fig. 2). The site was at the south-westerly part of the island (Fig. 3b) which is relatively flat, at a distance of $300 \mathrm{~m}$ from the ground height contour of $20 \mathrm{~m}$. As pure marine flow was considered for the wind directions that ranged from 270 to 345 degrees.

Meteorological masts were installed very close to the shoreline (at a distance of $30 \mathrm{~m}$ ), instrumented with a sonic anemometer and a fast open path hygrometer at the height of $10 \mathrm{~m}$ at Skyros site (Gill Wind Master, LICOR-7500) and at $14.5 \mathrm{~m}$ height at Karpathos site (Campbell

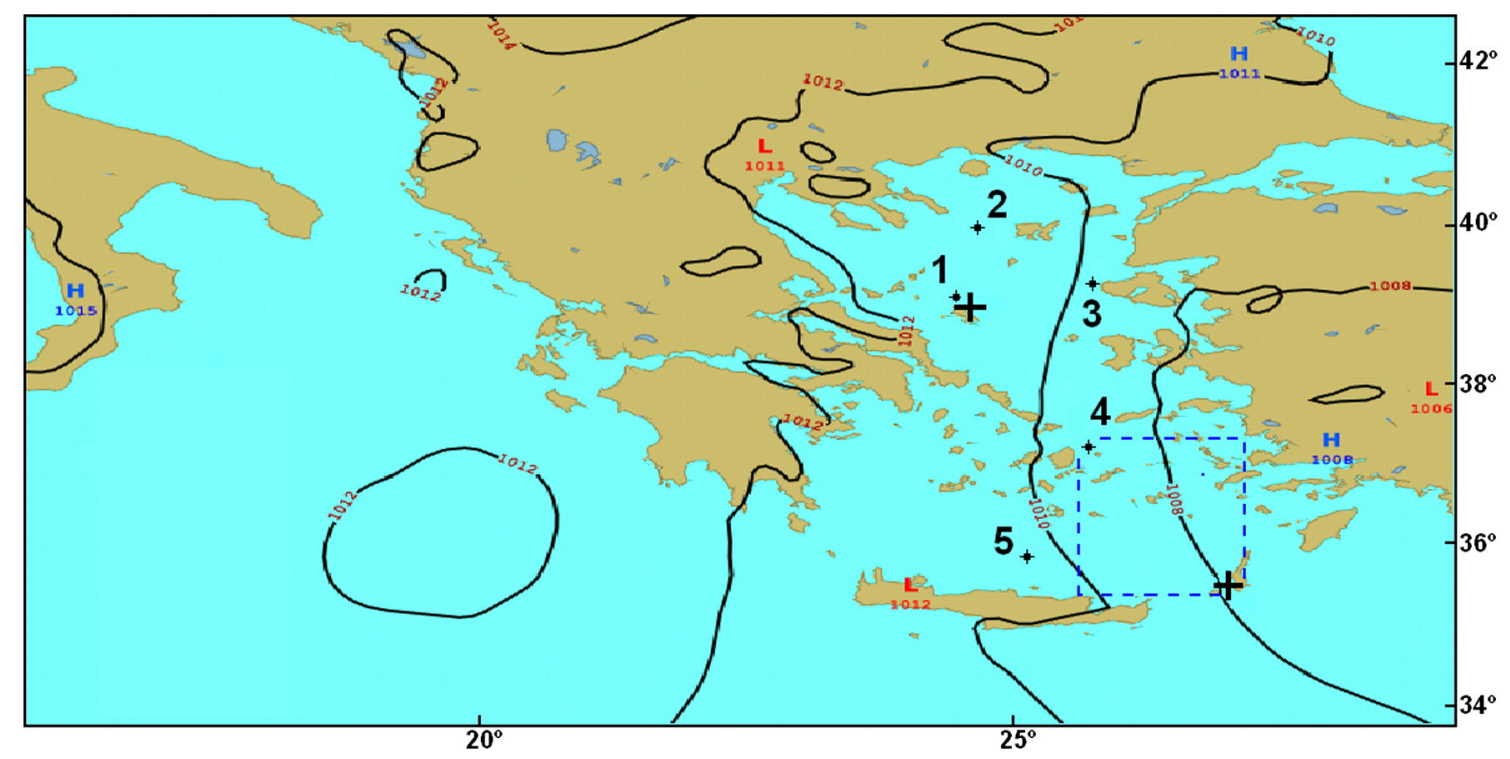

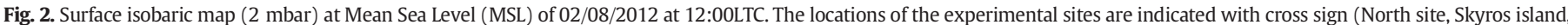

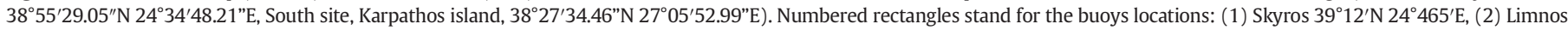

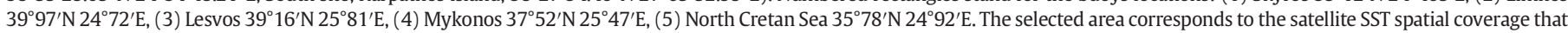
is presented in Figs. 9b, c, d, e. 


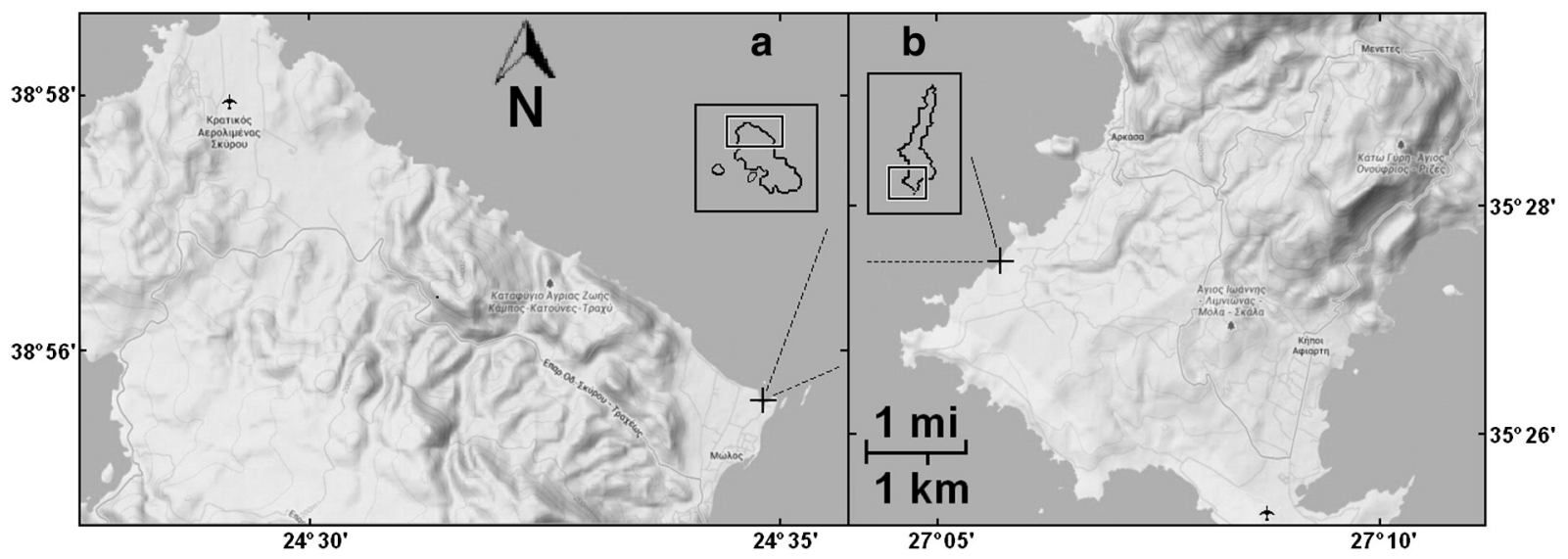

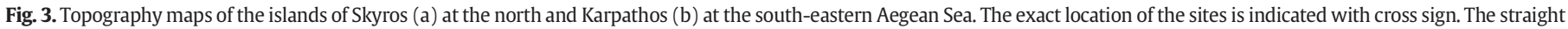
lines in both figures bound the wind direction range of pure marine flows for each site, as described in Section 2.2.

Scientific CSAT3 and KH20), in order to measure the three wind components, virtual temperature and water vapour density fluctuations with a sampling frequency of 20 and $10 \mathrm{~Hz}$ respectively. At the same masts slow response sensors provided measurements of the wind speed and direction, temperature and relative humidity ( $1 \mathrm{~Hz}$ sampling frequency) at three levels (2, 6 and $10 \mathrm{~m}$ at Skyros; 3, 9 and $13 \mathrm{~m}$ at Karpathos). A buoy located $36 \mathrm{~km}$ north-westerly from the site at Skyros ${ }^{1}$ and four other buoys of the Hellenic Centre of Marine Research (HCMR), operated near the islands of Limnos ${ }^{2}$, Lesvos ${ }^{3}$, Mykonos ${ }^{4}$ and north from Crete ${ }^{5}$ (see Figs. 2 and 4), provided additional meteorological (wind speed and direction and temperature, three hours averages) and sea state (temperature, significant wave height and period) data, during the first campaign while during the second, the great majority of these buoys were not in operation. Finally, sea surface temperature (SST) daily images with $1 / 16$ degrees resolution from the geosynchronous satellite INMARSAT-C were collected for both campaigns and atmospheric surface pressure records were obtained from the nearby airports located within $10 \mathrm{~km}$ distance from both sites (Fig. 3a and b) that were used for the calculations of sensible temperature and specific humidity.

It is worth to mention that the selection of the mast locations was based on the fact that the internal boundary layer (IBL) which forms due to the change in roughness and/or surface land heating (Garratt 1990), at a distance of $30 \mathrm{~m}$ from the shoreline was expected to be characterized with heights much less than the fluxes measuring height. The IBL's height is known to be a function of both roughness and downwind stability and it is reported to be greater under unstable conditions over the land (Savelyev and Taylor 2004). In order to reveal the influence of the developed IBL, the vertical temperature and humidity profiles from the slow response sensors were examined carefully for each $10 \mathrm{~min}$ segment in relation with the corresponding stability values estimated by the fast sensors at 10 and $14.5 \mathrm{~m}$ height. In most of the cases the IBL was affected mainly the layers close to the ground (from 2 to $6 \mathrm{~m}$ height at the north and 3 to $9 \mathrm{~m}$ at the south site) while the higher layers reveal the characteristics of the marine flow (near neutral or slightly stable conditions) that are in accordance with the estimated stability values from the fast sensors at 10 and $14.5 \mathrm{~m}$ height respectively. All the cases ( 10 min segments) where the influence of the IBL was evident at the higher level, for both sites, were excluded from the analysis.

\subsection{Data processing}

Data was initially treated with quality control procedures in order to find and exclude instrumentation errors. Recording gaps, values over

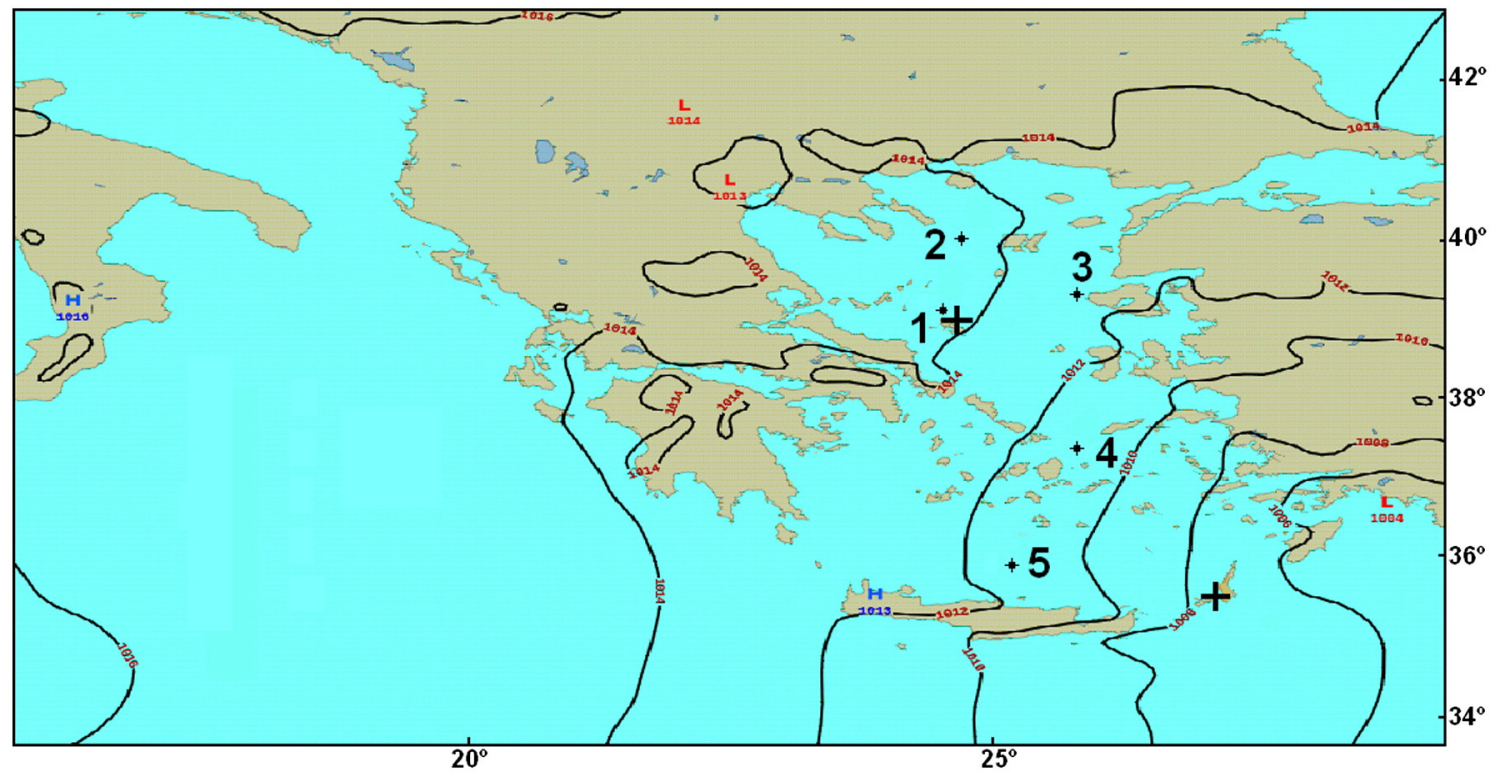

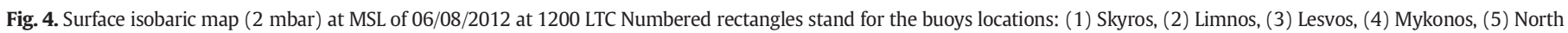
Cretan Sea. The locations of the experimental sites are indicated with cross sign. 


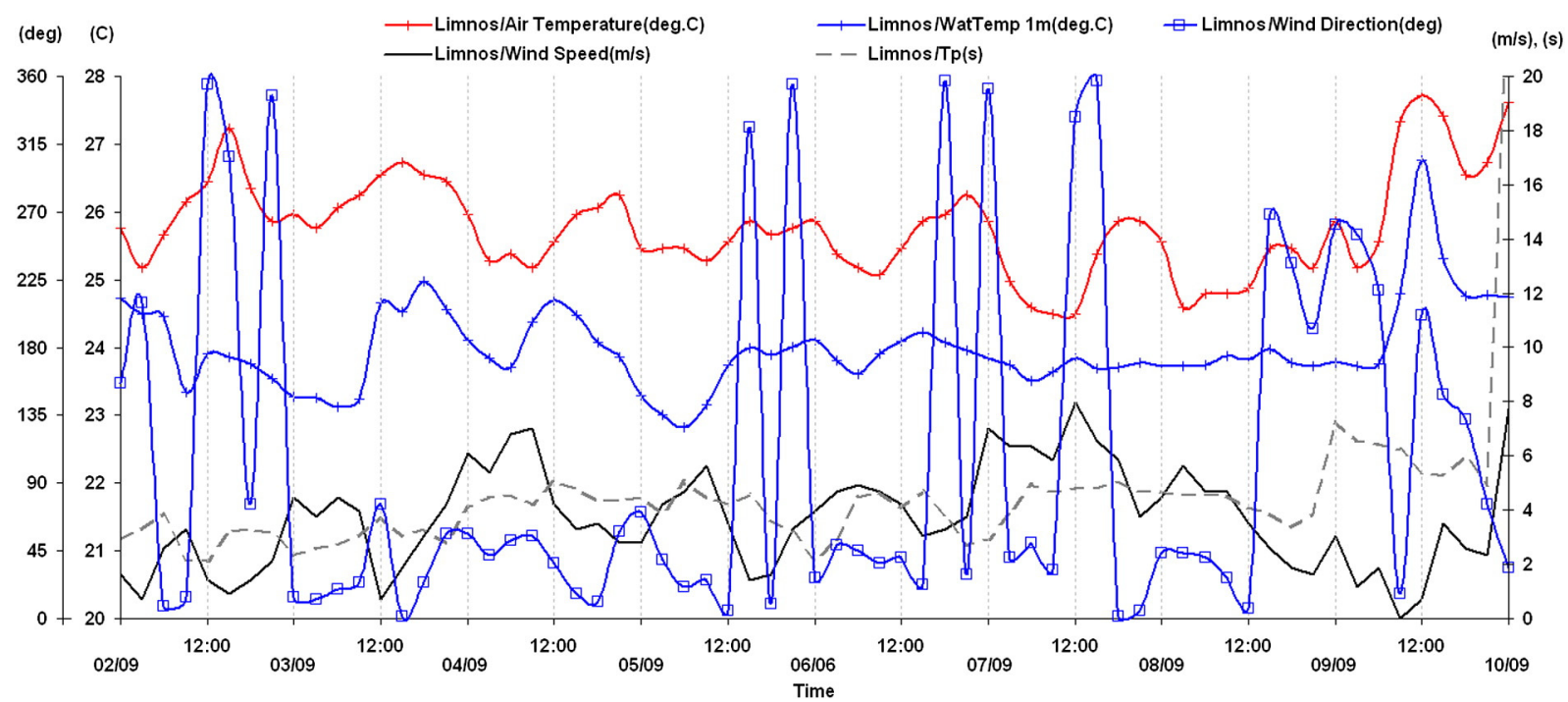

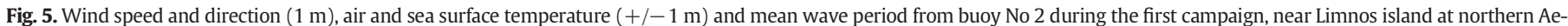
gean Sea (Fig. 2).

absolute limits and spikes were visually inspected and replaced with the average of their neighboring points, as suggested by Vickers and Mahrt (1997b). Less than $10^{-2} \%$ of corrections over about $10^{-1} \%$ of the total records were applied. Higher-moment tests (skewness and kurtosis) were also employed. About $0.5 \%$ of temperature and water vapor records at the south site and $7 \%$ of temperature and less than $1 \%$ of all wind components records at the north site were excluded from the analysis.

Tilt corrections were made using the planar fit method (Wilczak et al. 2001) in order to align the coordinate system with the mean flow streamlines, using $10 \mathrm{~min}$ average. The proposed orthogonality conditions were used, since the angles that were found (less than $10^{\circ}$ ) are considered as relatively large. According to Wilczak et al. (2001) due to the correction of tilt angles (around 10 degrees), a change in the corrected stress as large as $10 \%$ of the true stress should be expected, mostly at Karpathos records.

Records were furthermore examined for stationarity as proposed by Mahrt et al. (1996). Approximately 226 hours of observations (171 h from Karpathos and $55 \mathrm{~h}$ from Skyros data) of marine wind flow were available. The calculation of the turbulent fluxes was conducted using the eddy correlation analysis with averaging time of $10 \mathrm{~min}$. The Obukhov length over the sea is defined as

$\mathrm{L}=-\mathrm{u}_{*}^{3} \mathrm{~T}_{\mathrm{v}} / \mathrm{gk} \overline{\mathrm{w}^{\prime} \mathrm{T}_{\mathrm{v}}^{\prime}}$

where $\mathrm{u}_{*}=\left(\left(\overline{\mathrm{u}^{\prime} \mathrm{w}^{\prime}}\right)^{2}+\left(\overline{\mathrm{v}^{\prime} \mathrm{w}^{\prime}}\right)^{2}\right)^{1 / 4}$, is the friction velocity, $\mathrm{u}, \mathrm{v}$ and $\mathrm{w}$ are respectively the stream-wise, cross-stream and vertical components of wind, $T_{v}$ is the virtual temperature, $\overline{w^{\prime} T_{v}^{\prime}}$ is the virtual heat flux, $g$ the acceleration of gravity and $\mathrm{k}$ the von Karman constant $(\mathrm{k}=0.41)$. Absolute values of the stability parameter $(\mathrm{z} / \mathrm{L})$ less than 0.02 were considered that correspond to neutral conditions, where $z$ is the measuring height. Neutral values of wind speed at $10 \mathrm{~m}$ height for Skyros site were calculated as

$\mathrm{U}_{10 \mathrm{~N}}=\mathrm{U}_{10}+\left(\mathrm{u}_{*} / k\right) \ln (\mathrm{z} / \mathrm{L})$

The wind speed at $10 \mathrm{~m}$ for Karpathos data was produced using similarity theory wind profile equations, according to Large and Pond

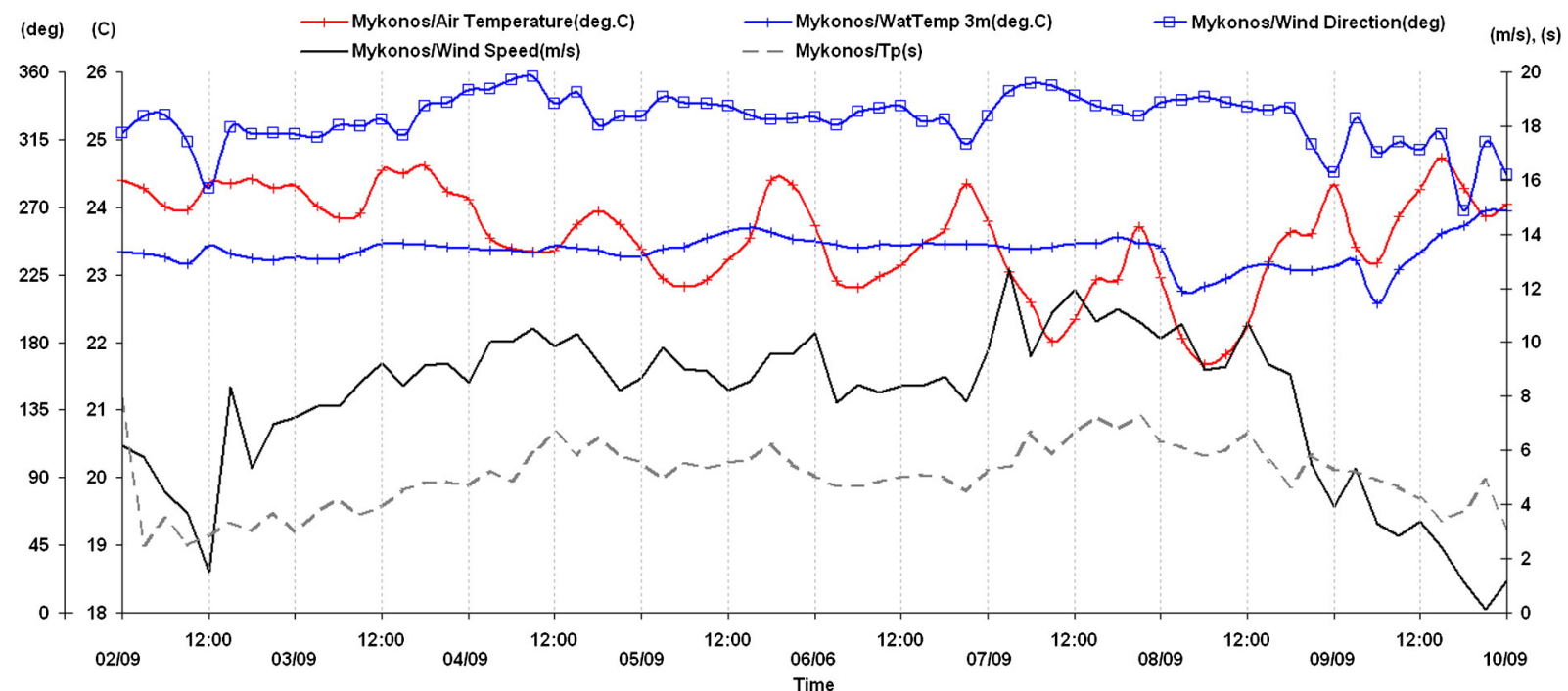

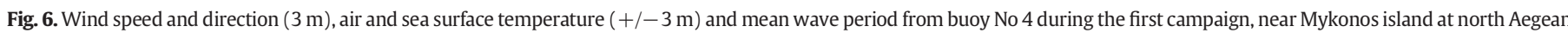
Sea (Fig. 2). 


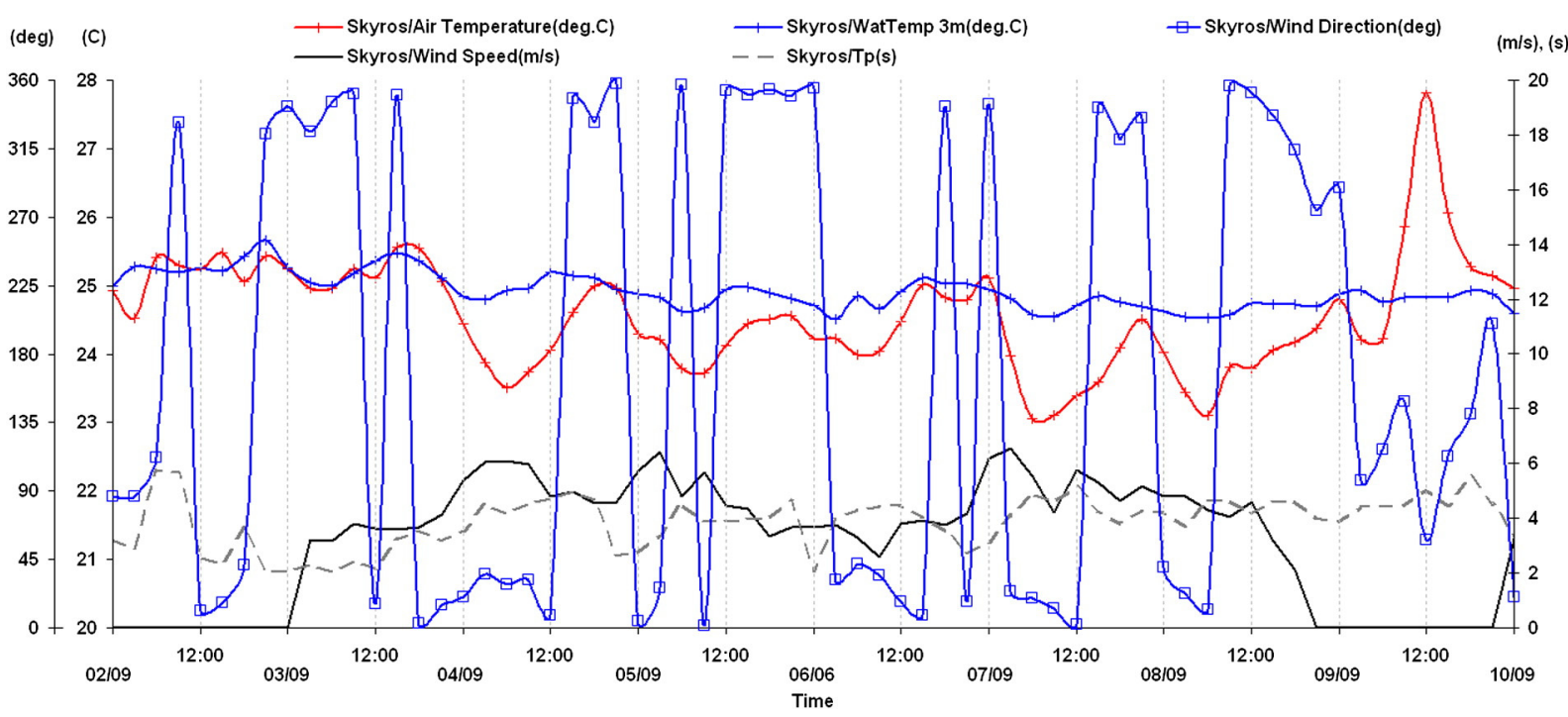

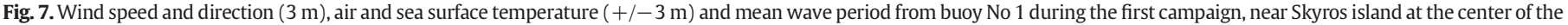
Aegean Sea (Fig. 2).

(1981) and neutral drag coefficient values were calculated according to the formula

$\mathrm{C}_{\mathrm{DN} 10}=\mathrm{C}_{\mathrm{D} 10}\left(1+\left(\mathrm{C}_{\mathrm{D} 10}{ }^{1 / 2}\right)(1 / k)(\psi(\mathrm{z} / \mathrm{L}))^{-2}\right.$

where $\psi(\mathrm{z} / \mathrm{L})$ is the dimensionless stability parameter as defined by Paulson (1970).

Sensible and latent heat fluxes were calculated using both sonic anemometer's and fast hydrometer's records that were available at the south site. Sensible temperature $\left(T_{s}\right)$ was calculated according to the formula

$\mathrm{T}_{\mathrm{s}}=\mathrm{T}_{\mathrm{v}}\left[1+\mathrm{T}_{\mathrm{v}}(1-\varepsilon) \rho_{v} \mathrm{R}_{\mathrm{v}} \mathrm{p}^{-1}\left(10^{-3}\right)\right]^{-1}$

, where $\rho_{v}$ is the absolute humidity, $\mathrm{p}$ is the atmospheric pressure, $\varepsilon$ $(=0.622)$ is the ratio $\left(R_{d} / R_{v}\right)$ of the universal gas constants of dry $\left(R_{d}\right)$ and moist air $\left(\mathrm{R}_{v}=461.5 \mathrm{JK}^{-1} \mathrm{~kg}^{-1}\right)$ respectively. Combined with the available satellite SST measurements, sensible temperature was used in order to estimate the air-sea temperature differences at the south site.

\section{Synoptic and surface conditions}

\subsection{Air-sea conditions}

During both campaigns, air temperature fluctuated from $25{ }^{\circ} \mathrm{C}$ to less than $31{ }^{\circ} \mathrm{C}$ at both sites, relative humidity from $50 \%$ to $85 \%$ and water vapor density from 15 to $20 \mathrm{gr} / \mathrm{m}^{3}$ (Karpathos records) at fluxes measurement height. Also, moderate to strong etesian winds were recorded that ranged up to $12 \mathrm{~m} / \mathrm{s}$ and wind direction varied from north to northwest (NW) at the south and from north to north-east (NE) at the north site (Figs. 7, 12). During the first campaign, buoys records additionally illustrated the dominant north direction of the etesian winds (Figs. 5, 6, 7, 8 ) while wind speed records also varied up to $12 \mathrm{~m} / \mathrm{s}$ at the centre Aegean (Fig. 6). The recorded mean wave periods that are also presented in Figs. 5 to 8 , ranged at all buoys locations from 2 to $8 \mathrm{~s}$ and revealed the dominance of wind driven waves (e.g. Hasselmann et al., 1973).

Regarding air-sea temperature difference values, apart from buoy No 5 (Fig. 8) at the south, all the other buoys which were located close to the eastern coasts, presented characteristics that are close to land's diurnal air temperature variation (Figs. 5, 6 and 7). In these figures as

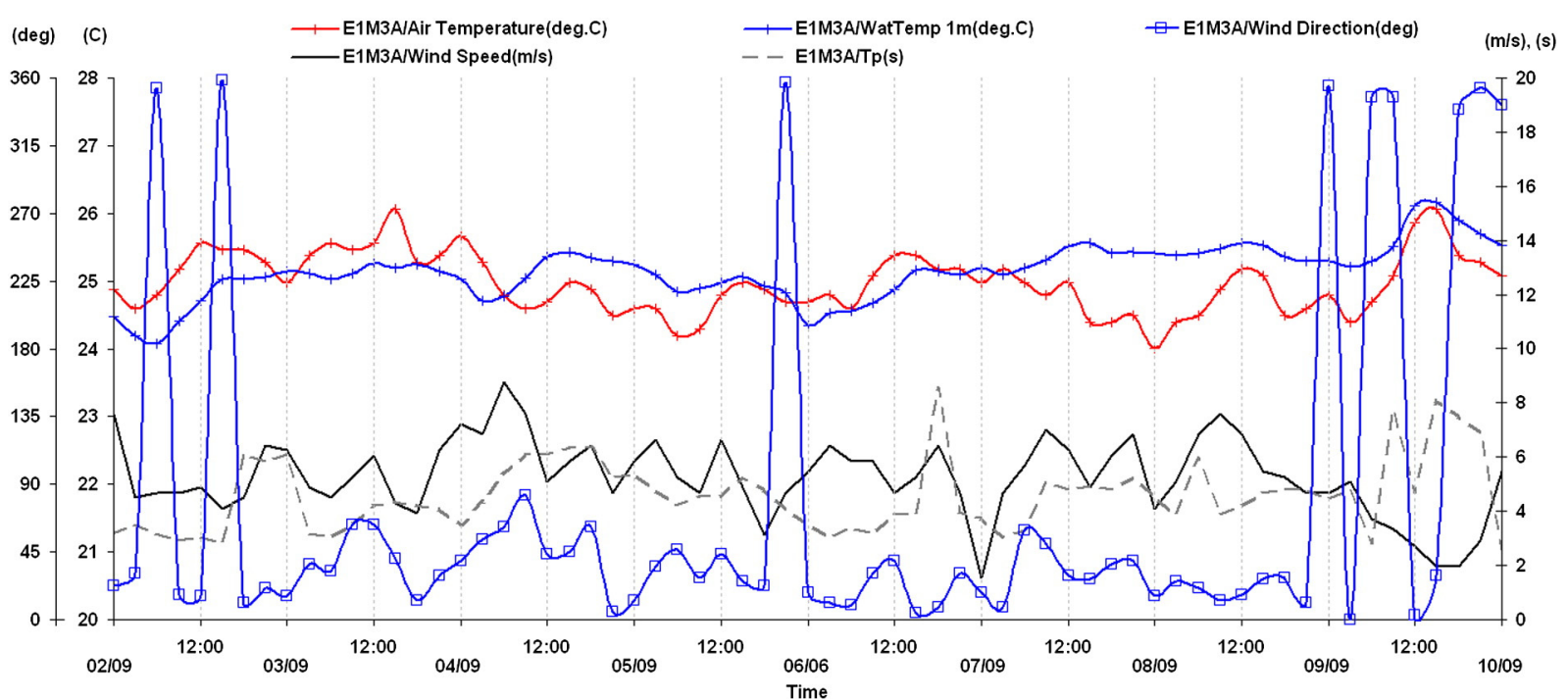

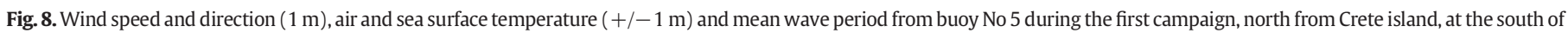
the Aegean Sea (Fig. 2). 


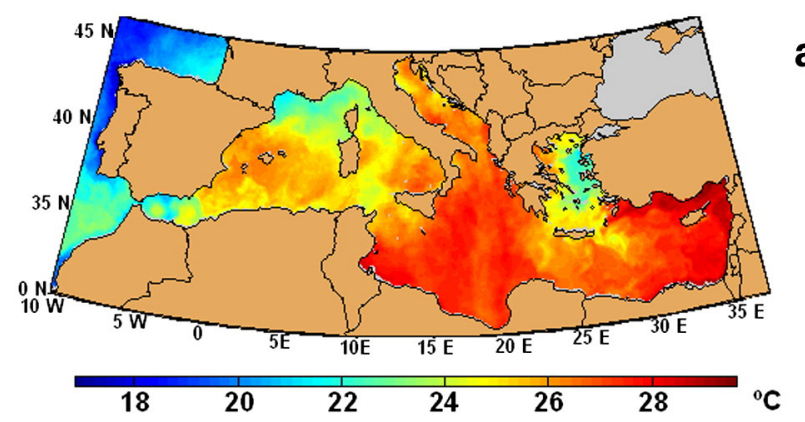

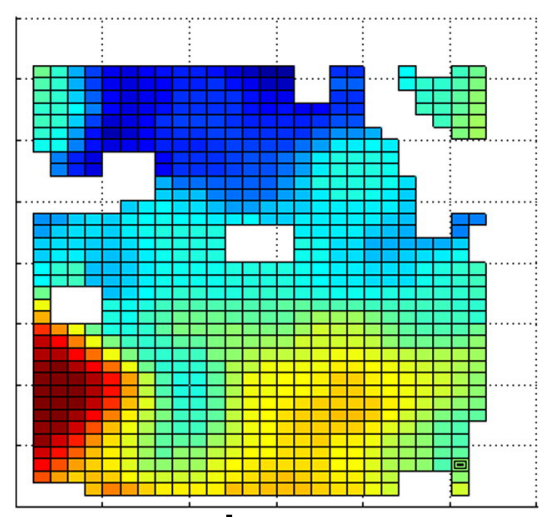

b
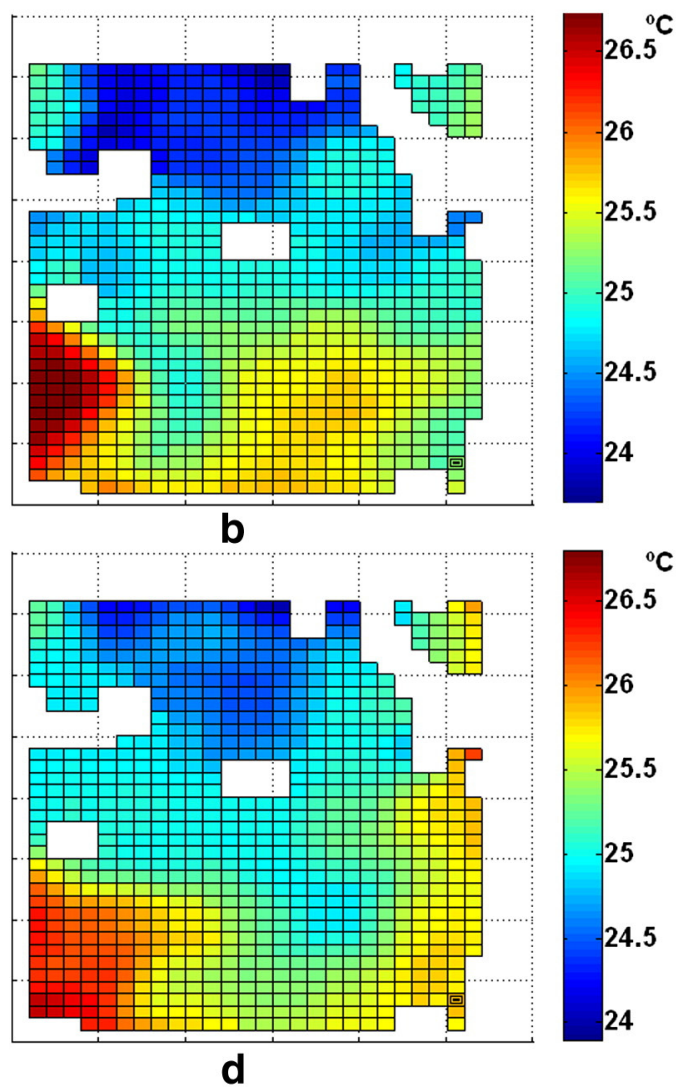

a

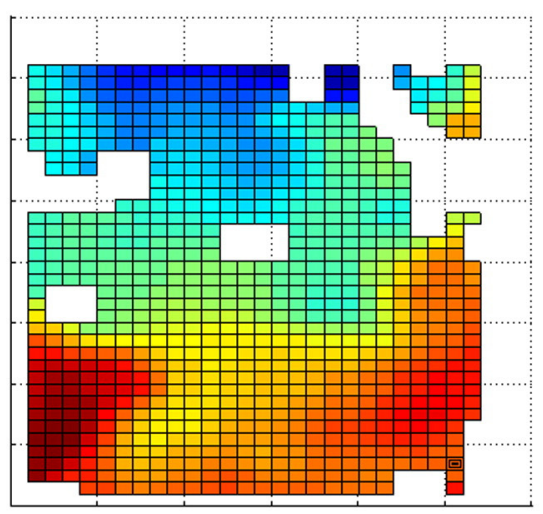

C

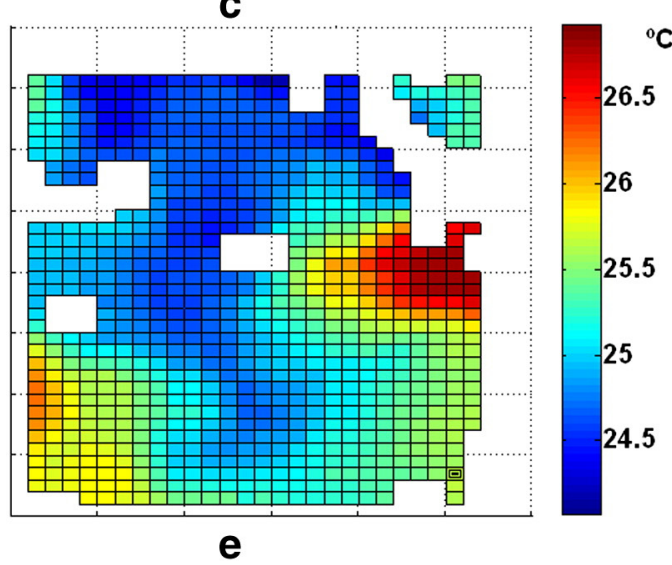

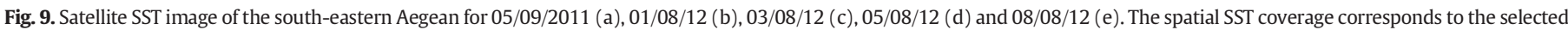
area seen in Fig. 2 . The grid $\left(\approx 6.5 \times 6.5 \mathrm{~km}^{2}\right)$ upwind the south site is marked.

well as in Fig. 10, where the prevailing conditions at the north site are presented, a daily variation of temperature over the sea is evident that was related with the advection few hours forward in time, depending on the wind direction and strength and the corresponding distance from the shores of Asia Minor. This fact resulted to air-sea temperature differences that ranged from -2 up to $4{ }^{\circ} \mathrm{C}$. Figs. 2 and 4 , present the change of the direction of the background flow with respect to the south site location, during the second experiment. At this site, when the direction of the background wind flow was parallel to the east coasts of Asia Minor (before August 5th, Fig. 2), air masses were brought from the center Aegean to the measuring site, with air temperature values close to SST ones and with no sign of diurnal variation (Fig. 12), similarly to buoy No 5 records during the first experimental period (Fig. 8). When the flow traveled from the southern-eastern coasts (after August 5th, Fig. 4), the air temperature presented diurnal variation with maximum temperature values found before or after sunset (Fig. 12).

This change of the direction of the background wind flow was also evident on the measured stability values of the air masses that became weak stable ( $44 \%$ of the data) from neutral $(51 \%)$ or slightly unstable (5\%) conditions $(-0.02>\mathrm{z} / \mathrm{L}>-0.04)$ during this second period. The limited range of the recorded wind direction values at the north site ( $\approx 45$ degrees), correspond to rather similar fetch conditions. The great majority of the flow records (97\%), were found to be characterized by neutral conditions while the remaining $3 \%$ records were characterized by slightly unstable conditions, which was probably due to the small negative air-sea temperature differences according to the near by buoy records (Fig. 10). This is in accordance with a recent study by Mahrt et al. (2012) according to which, the observed slightly unstable conditions are probably due to the increased sea surface temperature heterogeneity which was observed in our case upwind of both measuring sites (Fig. 9).

In fact, extended and variable spatial SST gradients were found all across the Aegean ( $\max \approx 1{ }^{\circ} \mathrm{C} / 50 \mathrm{~km}$ ), with cooler waters located from the center up to the north eastern coasts of the basin and temperature ranging from 22 to $26{ }^{\circ} \mathrm{C}$, during both experimental periods (Fig. 9). The observed SST gradient upwind the north site was constantly present during the first experimental period (Fig. 9a). At the south site, the SST field got warmer close to the site comparing to the center Aegean from the 1 st up to the 4th of August (Fig. 9b and c). In Fig. 12, we notice that during this period, very weak unstable conditions are recorded at the south site located downwind of the observed SST gradient. After 

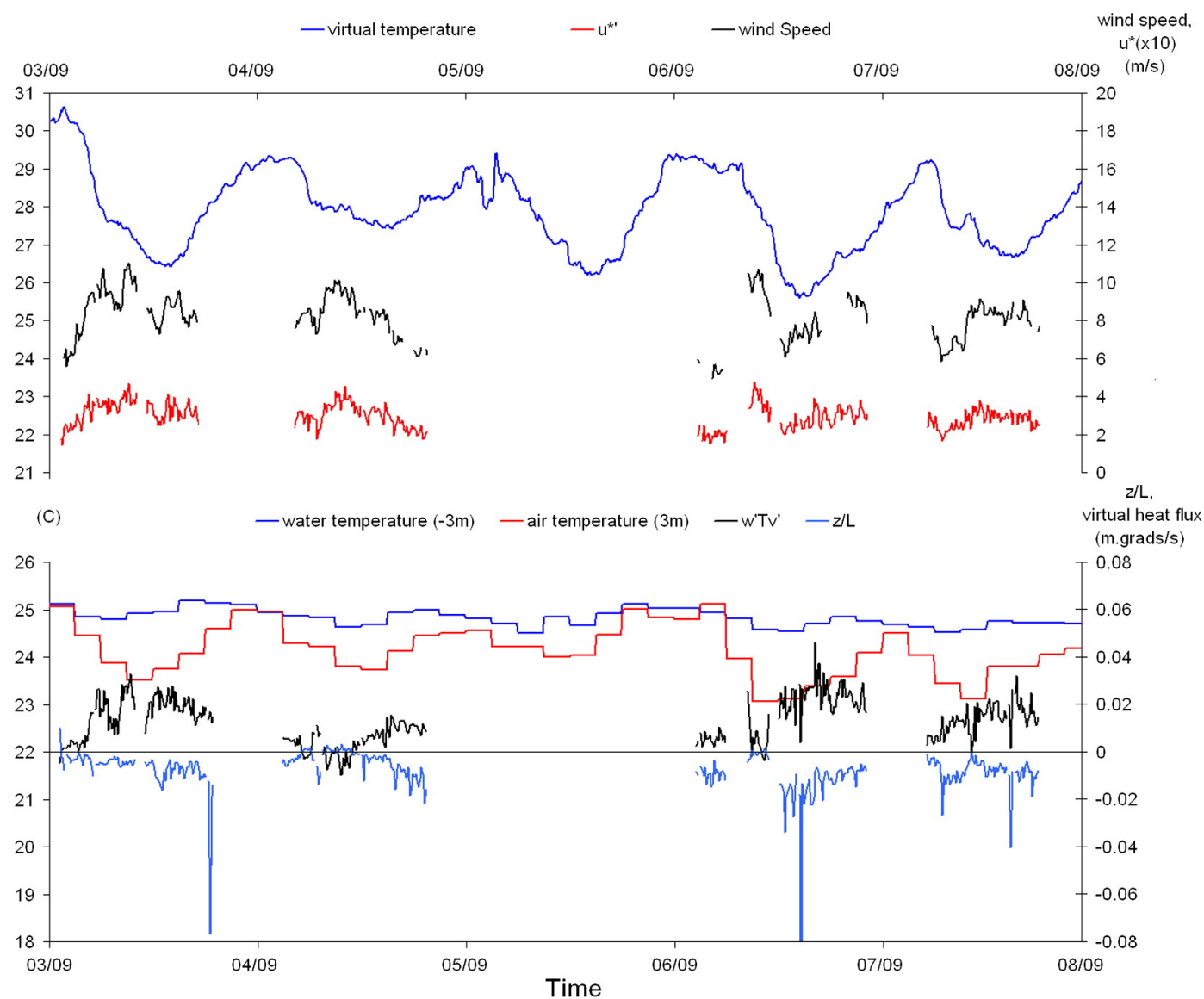

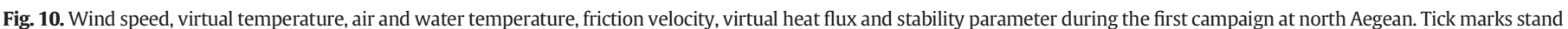
for 18:00 LTC.

the 5th of August, gradually developing warmer surface waters appeared at the south-eastern coasts of the basin and relatively cooler near the site (Fig. 9d, e). The slight increased stability conditions seen in Fig. 11 correspond to air-sea temperature differences up to 4 degrees and could be possibly due to phenomena (discussed in Section 3.2) related with the increased spatial SST variability that was observed upwind the south site. In the same figure (Fig. 11), where the scatter diagram of friction velocity $(\mathrm{u} *)$ towards stability parameter $(\mathrm{z} / \mathrm{L})$ is

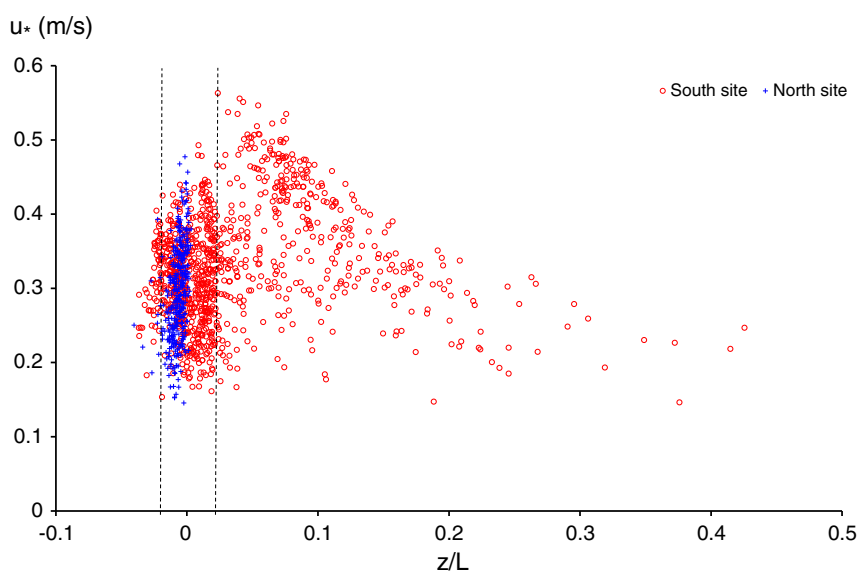

Fig. 11. Friction velocity versus stability parameter from both campaigns. Pairs of records $\left(\mathrm{z} / \mathrm{L}, \mathrm{u}^{*}\right)$ outside the presented range of stability are $(-0.17,0.23)$ for the north site and $(0.69,0.16),(0.94,0.13),(1.21,0.10),(1.43,0.17),(1.57,0.19)$ for the south site respectively. The vertical dashed lines bound the cases that are considered to respond to neutral conditions $(|z / L|<0.02)$. given, it is evident that the range of the recorded stability parameter values varies mainly from -0.04 up to 0.2 for both experiments, while the vertical dashed lines bound the cases under neutral conditions $(|z / L|<0.02)$ which are the majority of the observed values. It is also evident that friction velocity near neutral conditions presents a wide range of values which tend to increase as expected with decreasing stability.

\subsection{Surface heat and moisture fluxes}

Heat fluxes in general were found to augment with increasing friction velocity but primarily with the increase of temperature difference between the air and the sea that ranged from -1.5 to less than $0.5^{\circ} \mathrm{C}$ at the north and from -0.5 to $4{ }^{\circ} \mathrm{C}$ at the south site. Positive air-sea temperature differences result to negative heat fluxes and vise versa. The estimated virtual heat fluxes thus varied correspondingly from -10 to around $40 \mathrm{~W} / \mathrm{m}^{2}$ at the north and from -60 to less than $10 \mathrm{~W} / \mathrm{m}^{2}$ at the south. That was also the range of the calculated sensible heat flux (Fig. 12), since the latent heat flux appeared to be very small $\left(10^{-1}-10^{0} \mathrm{~W} / \mathrm{m}^{2}\right)$ and rarely reached values around $10 \mathrm{~W} / \mathrm{m}^{2}$. Under neutral stability conditions, moisture flux varied around zero (Fig. 12). Under weak stable conditions, moisture flux was mostly negative and varied proportionally with sensible heat flux (linear correlation $\mathrm{R}^{2}=0.68$ ). The observed downward fluxes corresponded to air flows from warmer towards cooler waters upwind the south measuring site and it should be mentioned that downward latent heat fluxes with values one order of magnitude greater have been observed to respond to sea fog events (Crofoot 2004). It is also worth to mention that similar studies of turbulent measurements of moisture under relevant conditions are not often found in the international literature. 


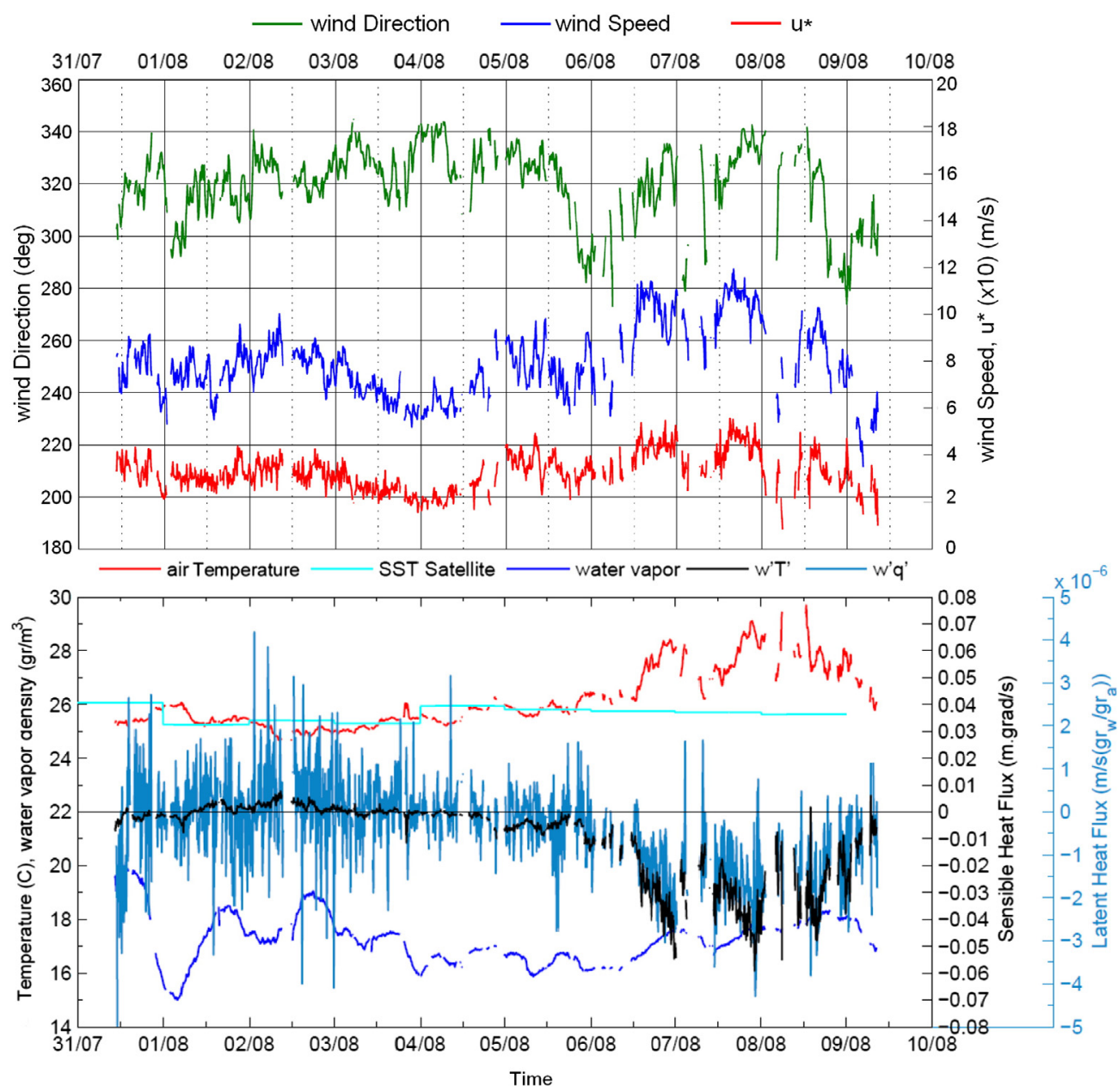

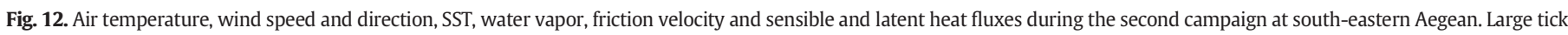
marks stand for 00:00 and small for 12:00 LTC.

In Fig. 12, the records of water vapor density presented a type of diurnal variation which after the 5th of August was also related to the observed daily variation of air temperature. The fact that water vapor density increment was accompanied by downward latent heat fluxes with a similar increasing trend, gives evident that the fine scales of the Aegean combined with the observed intense spatial and temporal variability of the SST, are most possibly responsible for phenomena related with the surface marine TIBL formations that can locally set the direction of the heat and moisture transfer and alter the temperature and moisture content of the air. Relevant measurements and simulations over SST variations of small spatial scales $\left(10^{0}-10^{1} \mathrm{~km}\right)$ and magnitude during the CBLAST experiment (Edson et al. 2007), have revealed the difficulty to parameterize the response of the MABL when the air flow passes from warm to colder waters and vise versa on such scales.

Finally, it should be noted that the observed behavior of air temperature over the Aegean which drive the sign and magnitude of virtual heat fluxes, could be of some importance regarding the loss of heat from the sea surface, since the estimated annual mean net heat flux for the Aegean sea is at $26 \mathrm{~W} / \mathrm{m}^{2}$ (Poulos et al. 1997) implying that the Aegean Sea, on the average, is losing heat through its surface.

\section{Momentum fluxes over the Aegean Sea}

\subsection{Wind stress and bulk parameterization}

According to Fig. 11 the friction velocity (under neutral or very weak unstable conditions) does not give any certain relation with stability.
Under slightly stable conditions $(\mathrm{z} / \mathrm{L} \approx 0.05-0.1)$, large values of friction velocity were found at the south site, which were decreasing with increasing stability values (around $50 \%$ for $\mathrm{z} / \mathrm{L} \approx 0.2$ ). It is worth mentioning that high linear correlation values were found between friction velocity and wind speed $\left(U_{10 N}\right)$ from both sites records, with $\mathrm{R}^{2}=0.82$ at the north and $\mathrm{R}^{2}=0.73$ at the south Aegean respectively. As seen in Fig. 13, which gives the friction velocity versus wind speed at $10 \mathrm{~m}$ height, and according to Table 1, the two regression lines corresponding to the north (NA) and the south Aegean (SA) data respectively, give almost the same slope while their addend terms vary within the resulting root mean square error (RMSE). Table 1 gives the corresponding regression equations that seem to extend locally and for moderate winds the linearity between friction velocity and wind speed that was proposed from Foreman and Emeis (2010) for the range 8-30 m/s using their extended dataset, which also includes FETCH experiment records over the western Mediterranean Sea.

It is worth mentioning that, the change in the direction of the background wind flow before and after the 5th of August was also noticeable at the friction velocity records. Although friction velocity at both north and south-eastern Aegean, was found to be described by nearly identical (within the resulting RMSE) linear regression equations with wind speed, careful selection and examination of the south site records based on the 6 hour isobaric charts, revealed an increase of the slope of the regression line for the data that corresponded to air flows over the extended spatial SST gradient seen in Fig. 9b and c. The SST gradient reached values up to $1{ }^{\circ} \mathrm{C}$ over $50 \mathrm{~km}$, while slightly unstable conditions were observed on the site during that period (Fig. 12). Since only one 


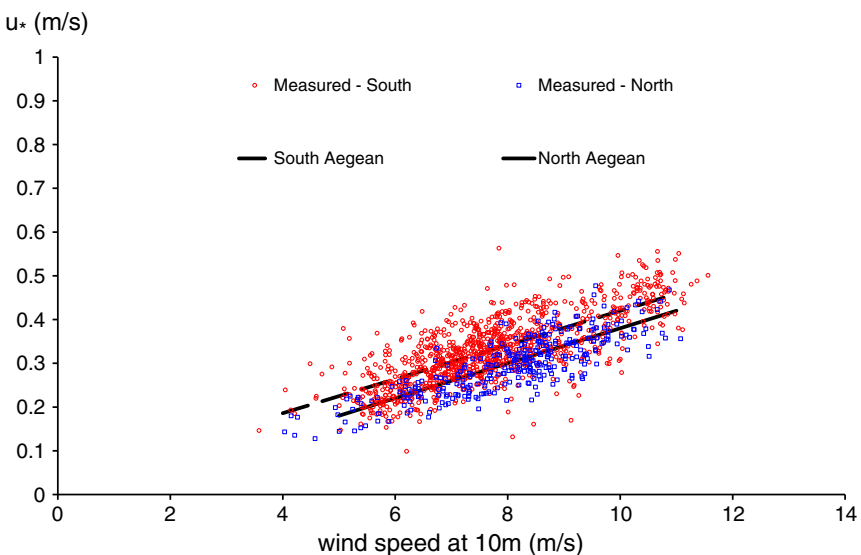

Fig. 13. Friction velocity versus neutral wind speed at $10 \mathrm{~m}$ and the corresponding regression curves.

point for measurements was available, it is not possible to pursue the question whether this increase is related to air flow acceleration caused by the observed spatial SST gradient even though relative phenomena have been observed for gradient values of $2{ }^{\circ} \mathrm{C} / 100 \mathrm{~km}$ (Small et al. 2008).

\subsection{Drag coefficient}

Fig. 14 gives the scatter diagram of the neutral wind speed and drag coefficient values at $10 \mathrm{~m}$ height that were calculated according to Section 2.3 at the two sites. Drag coefficient values at the south site generally show a slight tendency to increase with wind speed up to $8 \mathrm{~m} / \mathrm{s}$, over which is rather constant for the south site's records. It is worth mentioning that the drag coefficient values and their neutral estimations varied very little over the range of the observed weak stable conditions during the experiment (not shown). In total, $\mathrm{C}_{\mathrm{DN} 10}$ values were found to be higher, almost by a factor of two, compared to the typical values measured over the ocean (Garratt 1977, Large and Pond 1981, Smith and Banke 1975). The enhanced values found over south Aegean for wind speed lower than $8 \mathrm{~m} / \mathrm{s}$, were related mostly with background wind flow directions from the centre Aegean. Similar increased values have been reported from measurements over the Kattegat Sea (Busch 1977), which is a semi-closed part of the North Sea, with unobstructed fetch of $135 \mathrm{~km}$, no swell and relatively shallow waters. At the north Aegean, $C_{\mathrm{DN} 10}$ values were found also to be relatively enhanced and almost constant over the whole wind speed range. During the FETCH experiment, under limited and unobstructed fetch wind directions with similar scales (around $50 \mathrm{~km}$ ) and wind speed range, increased drag coefficient values were also found (Drennan et al. 2003). These values which correspond to pure or dominant wind sea conditions, were generally underestimated but still best described by Smith's (1980) relation and were very close to the north site's observations.

The mean $10^{3} \cdot C_{\mathrm{DN} 10}$, from the 226 hours of observations of similar limited fetch conditions from the north and the south-eastern Aegean and for wind speed values from 4 to $11 \mathrm{~m} / \mathrm{s}$, is 1.72 . The relatively small differences of drag coefficient values that were found between the north and the south site records could possibly reflect the changes in the complexity of the topography upwind the two sites (i.e. channeling effects between the various islands, wave development).

Table 1

Regression formulas of the friction velocity with wind speed at $10 \mathrm{~m}$.

\begin{tabular}{lll}
\hline Campaign & $\begin{array}{l}\mathrm{u}^{*} \\
(\mathrm{RMSE})\end{array}$ & Range $\mathrm{U}_{10}(\mathrm{~m} / \mathrm{s})$ \\
\hline South Aegean (SA) & $0.039 \mathrm{U}_{10}+0.03( \pm 0.05)$ & $4-11$ \\
North Aegean (NA) & $0.040 \mathrm{U}_{10}-0.02( \pm 0.04)$ & $4-11$ \\
\hline
\end{tabular}

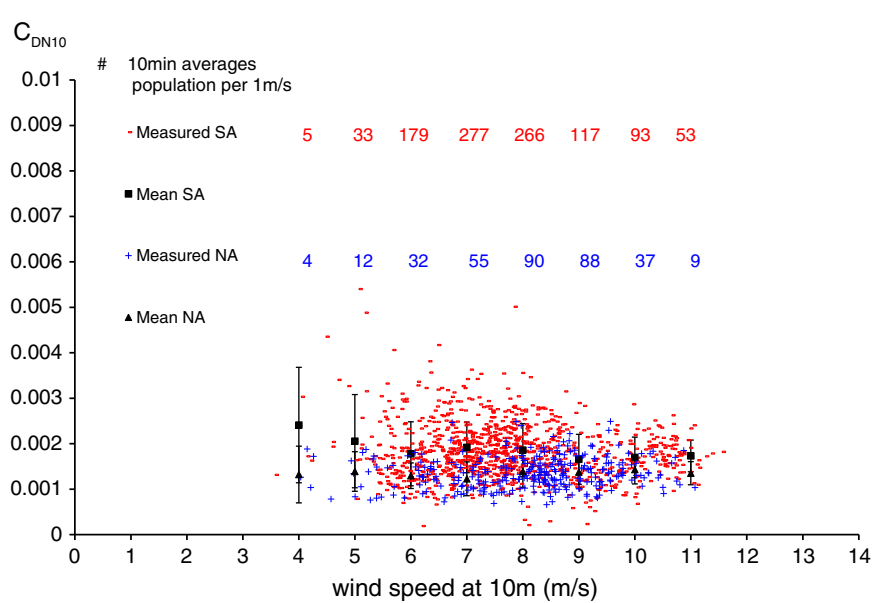

Fig. 14. Neutral drag coefficient versus neutral wind speed at $10 \mathrm{~m}$ at both sites. The error bars, represent the standard deviation over the mean of $C_{\mathrm{DN} 10}$ values on each wind speed bin.

\section{Conclusions}

Turbulent fluxes within the surface MABL were measured from meteorological masts at the shoreline of two islands with different fetch, at the northern and at the south-eastern area of the Aegean Sea, during summer 2011 and 2012 respectively. The atmospheric conditions during both experiments were found to correspond mostly to neutral conditions at both sites. According to the results, it became evident that the short fetch of the air flow especially over the centre and north Aegean, leads to diurnal air temperature variations which depending on the local SST, drive the magnitude as well as the sign of the surface heat fluxes. The recorded fluxes augmented mainly with increasing temperature differences that ranged from -1.5 to $4{ }^{\circ} \mathrm{C}$ in total at the two sites and varied from -10 to $40 \mathrm{~W} / \mathrm{m}^{2}$ at the north and from -60 to $10 \mathrm{~W} / \mathrm{m}^{2}$ at the south site. Moisture fluxes were also found affected by the limited spatial and temporal scales of the responding air-sea interaction mechanism, when air flows from warmer to cooler waters resulted to small downward moisture fluxes that ranged up to few $\mathrm{W} / \mathrm{m}^{2}$, under very weak stable conditions.

The available buoys records during the first experiment revealed wind driven wave's dominance all over the region. Friction velocity values were found to be a linear function of wind speed in both sites while drag coefficient values were found higher up to a factor of two, compared to typical values measured over the ocean. The proposed parameterization of the drag coefficient at $10 \mathrm{~m}$ height is a constant function of wind speed (1.72) for wind speed values in the range from 4 to $11 \mathrm{~m} / \mathrm{s}$. These enhanced values of drag coefficient should be attributed probably to the limited and variable fetch conditions within the complex topography of the semi-closed sea of the Aegean Sea.

\section{Acknowledgments}

This research has been co-financed by the European Union (European Social Fund - ESF) and Greek national funds through the Operational Program "Education and Lifelong Learning" of the National Strategic Reference Framework (NSRF) - Research Funding Program: Heracleitus II, Investing in knowledge society through the European Social Fund. The authors also gratefully acknowledge Lecturer Dr. Sofianos S. for providing the daily SST images from the satellite INMARSAT-C and HCMR buoys data, Sqn Ldr Armenis G. meteorologist at the Hellenic National Meteorological Service for providing weather maps and near by airports meteorological data during the experiments, researcher Dr. Halios C. for his contribution in calibration of instruments, post-graduate student Moushouras P. for his contribution in the analysis of data and undergraduates 
Arnaoutis S. and Gialitaki A. for their contribution in the experimental campaigns.

\section{References}

Andreas EL. Spray-Mediated Enthalpy Flux to the Atmosphere and Salt Flux to the Ocean in High Winds. J Phys Oceanogr 2010;40:608-19. http://dx.doi.org/10.1175/ 2009JPO4232.1. [Mar].

Busch NE. Fluxes in the surface boundary layer over the sea. Modeling and Prediction of the Upper Layer of the Ocean. Proceedings of a NATO Advanced Study Institute; 1975. Urbino, Italy. New York: Pergamon Press; 1977.

Byrne HM. The variation of the drag coefficient on the marine surface layer due to temporal and spatial variations of the surface wind and sea state. NOAA Technical Memorandum ERL PMEL-49. Seattle, Washington: Pacific Marine Environmental Laboratory; 1983 [Jun].

Crofoot RF. Investigations of scalar transfer coefficients in fog during the Coupled Boundary Layers and Air-Sea Transfer experiment: A case study. M.S. Thesis Joint Program in Applied Ocean Science and Engineering, the Woods Hole Oceanographic Institution. Cambridge, MA: Massachusetts Institute of Technology, Department of Ocean Engineering; 2004.

Drennan WM, Graber HC, Hauser D, Quentin C. On the wave age dependence of wind stress over pure wind seas. J Geophys Res 2003;108(C3):8062. http://dx.doi.org/10.1029/ 2000JC000715.

Edson J, Crawford T, Crescenti J, Farrar T, French J, Frew N, et al. The Coupled Boundary Layers and Air-Sea Transfer Experiment in Low Winds (CBLAST-LOW. Bull Am Meteorol Soc 2007;88:341-56. http://dx.doi.org/10.1175/BAMS-88-3-341. [Mar]

Foreman RJ, Emeis S. Revisiting the Definition of the Drag Coefficient in the Marine Atmospheric Boundary Layer. J Phys Oceanogr 2010;40:2325-32. http://dx.doi.org/10. 1175/2010JPO4420.1. [Oct].

Frieche CA, Shaw WJ, Roger DP, Davidson KL, Large WG, Stage SA, et al. Air-sea fluxes and surface layer turbulence around a sea surface temperature front. J Geophys Res 1991: 96:8593-609. http://dx.doi.org/10.1029/90JC02062. [Sep].

Gao ZQ Wang Q, Zhou MY. Wave-dependence of friction velocity, roughness length, and drag coefficient over coastal and open water surfaces by using three databases. Adv Atmos Sci 2009;26:887-94. http://dx.doi.org/10.1007/s00376-009-8130-7. [Sep].

Garratt J. Review of Drag Coefficients over Oceans and Continents. Mon Weather Rev 1977;105:915-29. http://dx.doi.org/10.1175/1520-0493(1977)105<0915: RODCOO $>2.0 . C O ; 2$. [Jul].

Garratt JR. The internal boundary layer - A review. Bound-Layer Meteorol 1990;50(1-4): 171-203. http://dx.doi.org/10.1007/BF00120524. [Mar].

Geernaert G, Katsaros KB. Incorporation of Stratification Effects on the Oceanic Roughness Length in the Derivation of the Neutral Drag Coefficient. J Phys Oceanogr 1986;16: 1580-4. http://dx.doi.org/10.1175/1520-0485(1986)016<1580:IOSEOT>2.0.CO;2. [Feb].

Geernaert GL, Plant WJ. Surface Waves and Fluxes: Current theory. The Netherlands: Kluwer; 1990.

Hasselmann K, Barnett PT, Bouws E, Carlson H, Cartwright DE, Enke K, et al. Measurements of wind-wave growth and swell decay during the Joint North Sea Wave Project (JONSWAP). Dtsch Hydrogr Z 1973;12:1-95.

Hauser D, Branger H, Bouffies-Cloché S, Despiau S, Drennan WM, Dupuis H, et al. The FETCH experiment: An overview. J Geophys Res 2003;108:8053. http://dx.doi.org/ 10.1029/2001JC001202. [Mar].

Hwang PA. Temporal and spatial variation of the drag coefficient of a developing sea under steady wind-forcing. J Geophys Res: Oceans 2005;110(C7). http://dx.doi.org/ 10.1029/2005JC002912. [Jul].

Hwang PA, Garcíía-Nava H, Ocampo-Torres FJ. Dimensionally Consistent Similarity Relation of Ocean Surface Friction Coefficient in Mixed Seas. J Phys Oceanogr 2011: 41(6):1227-38. http://dx.doi.org/10.1175/2011JPO4566.1. [Jun].

Large WG, Pond S. Open sea momentum flux measurements in moderate to strong winds. J Phys Oceanogr 1981;11:324-36. http://dx.doi.org/10.1175/1520-0485(1981) $011<0324$ :OOMFMI $>2.0 . \mathrm{CO} ; 2$. [Nov].
Mahrt L, Vickers D, Howell J, Hojstrup J, Wilczak JM, Edson J, et al. Sea surface drag coefficients in the Riso Air Sea Experiment. J Geophys 1996;101:14327-35. http://dx.doi. org/10.1029/96JC00748. [Jun]

Mahrt L, Vickers D, Andreas E, Khelif D. Sensible Heat Flux in Near-Neutral Conditions over the Sea. J Phys Oceanogr 2012;42:1134-42. http://dx.doi.org/10.1175/JPO-D11-0186.1. [Feb]

Paulson CA. The Mathematical Representation of Wind Speed and Temperature Profiles in the Unstable Atmospheric Surface Layer. J Appl Meteorol 1970;9:857-61. http://dx doi.org/10.1175/1520-0450(1970)009<0857:TMROWS>2.0.CO;2. [Dec].

Pedreros R, Dardier G, Dupuis H, Graber HC, Drennan WM, Weill A, et al. Momentum and heat fluxes via the eddy correlation method on the R/V L'Atalante and an ASIS buoy. J Geophys Res 2003;108. http://dx.doi.org/10.1029/2002JC001449. [Nov].

Pond S, Pickard GL. Introductory Dynamical Oceanography. 2nd ed. Oxford: Pergamon; 1983.

Poulos SE, Drakopoulos PG, Collins MB. Seasonal variability in sea surface oceanographic conditions in the Aegean Sea (Eastern Mediterranean): an overview. J Mar Syst 1997; 13:225-44. http://dx.doi.org/10.1016/S0924-7963(96)00113-3. [Oct].

Rizou D, Flocas H, Bartzokas A, Helmis CG. On the link between Indian summer monsoon and the Etesian pattern over the Aegean Sea. CEST 2013: Proceedings of the 13th International Conference on Environmental Science and Technology; 2013. [Sep 5-7, Athens, Greece].

Savelyev S, Taylor P. Internal Boundary Layers: I. Height Formulae for Neutral and Diabatic Flows. Bound-Layer Meteorol 2004;115:1-25. http://dx.doi.org/10.1007/ s10546-004-2122-z. [Jul].

Sethuraman S, Raynor GS. Surface drag coefficient dependence on the aerodynamic roughness of the sea. J Geophys Res 1975;80(36):4983-8. http://dx.doi.org/10. 1029/JC080i036p04983. [Dec].

Skliris N, Sofianos S, Gkanasos A, Axaopoulos P, Mantziafou A, Vervatis V. Long-term sea surface temperature variability in the Aegean Sea. Adv Limnog Oceanogr 2011; 2(2):125-39. http://dx.doi.org/10.1080/19475721.2011.601325. [Nov].

Small RJ, deSzoeke SP, Xie SP, O'Neill L, Seo H, Song Q et al. Air-sea interaction over ocean fronts and eddies. Dyn Atmos Oceans 2008;45(3-4):274-319. http://dx.doi.org/ 10.1016/j.dynatmoce.2008.01.001. [Jul].

Smedman AS, Larsén XG, Högström UH, Kahma K, Pettersson H. Effect of the sea state on the momentum exchange over the sea during neutral conditions. J Geophys Res 2003;108(C11):3367. http://dx.doi.org/10.1029/2002JC001526. [Nov].

Smith SD. Wind Stress and Heat Flux over the Ocean in Gale Force Winds. J Phys Oceanogr 1980;10:709-26. http://dx.doi.org/10.1175/1520-0485(1980)010<0709:WSAHFO >2. $0 . \mathrm{CO} ; 2$. [May].

Smith SD, Banke EG. Variation of the sea surface drag coefficient with wind speed. Q J R Meteorol Soc 1975;101:665-73. [Dec, 551.551.8:551.465.752].

Smith SD, Fairall CW, Geernaert GL, Hasse L. Air-sea fluxes: 25 years of progress. BoundLayer Meteorol 1996;78:247-90. http://dx.doi.org/10.1007/BF00120938. [Oct].

Sofianos S, Johns W, Lascaratos A, Murray S, Olson D, Theocharis A. Draft Report of the Aegean Sea Workshop. Proceedings of the Aegean Sea Workshop. Rhodes, Greece: Sponsored by the Office of Naval Research and Office of Naval Research International Field Office; 2002. [Oct 8-10, Available from: http://www.oc.phys.uoa.gr/workshop/ Aegean_Draft_Report_f.htm].

Vickers D, Mahrt L. Fetch limited drag coefficients. Bound-Layer Meteorol 1997a;85(1) 53-79. http://dx.doi.org/10.1023/A:1000472623187. [Apr].

Vickers D, Mahrt L. Quality Control and Flux Sampling Problems for Tower and Aircraft Data. J. Atmos. Ocean. Technol. 1997b;14:512-26. http://dx.doi.org/10.1175/1520 0426(1997)014<0512:QCAFSP>2.0.CO;2. [Jun].

Vihma T, Uotila J, Launiainen J. Air-sea interaction over a thermal marine front in the Denmark Strait. J Geophys Res 1998;103(C12):27665-78. http://dx.doi.org/10.1029/ 98JC02415. [Sep].

Volkov YA. Turbulent flux of momentum and heat in the atmospheric surface layer over disturbed sea-surface. Izv Acad Sci USSR Atmos Oceanic Phys Engl Transl 1970;6: 770-4.

Wilczak JM, Oncley SP, Stage SA. Sonic anemometer tilt correction algorithms. BoundLayer Meteorol 2001;99:127-50. http://dx.doi.org/10.1023/A:1018966204465. [Jul]. 